\title{
Проблемы циркумфиксации
}

Р. Г. Гатауллин

Башкирский государственный университет

Россия, Республика Башкортостан, 450076 г. Уфа, улица Заки Валиди, 32.

Email: gataullinrg@lisr.ru

Анализируется циркумфиксация (также комбинационная деривация kombinatorische Derivation) - создание слов путем одновременного прибавления к производящей основе и приставки, и суффикса. При циркумфикации основная морфема «расширяется аффиксом как в начале, так и в конце одновременно», при этом оба аффикса выступают всегда совместно. Циркумфиксация рассматривается одним из основных видов деривации наряду с суффиксацией и префиксацией.

Ключевые слова: деривация, циркумфикс, циркумфиксация, дискретный аффикс, суффикс.

В деривационных исследованиях последних лет в качестве новых форм аффиксации выдвигаются циркумфиксация (Zirkumfigierung) и инфиксация (Infigierung) [1]. Обычно под «инфиксом» понимают аффиксальную морфему внутри другой морфемы: Hinge-laufe, entscheidungs-un-freudig. Часто к инфиксам относят ge- и zи внутри грамматических форм глаголов с отделяемыми приставками auf-ge-hör-t, auf-zu-hör-en, где они нередко являются составной частью циркумфикса [2, с. 67]. Флейшер/ Барц констатируют: „Nach ihrer Position sind Affixarrten Präfix, Suffix und Zirkumfix zu unterscheiden». По своей позиции в структуре слова различаются следующие виды аффиксов: префиксы, суффиксы и циркумфиксы. Соединяясь с основами слов, синтагмами или конфиксами, они образуют сложные лексемы. Префиксы находятся слева от производящей (деривационной) основы, а суффиксы - справа. Циркумфиксы окружают основу“ [3, с. 54]. Такая позиция представлена в исследованиях по словообразованию института немецкого языка (Маnnheim-Мангейм): „In der deutschen Wortbildung werden explizite Derivate vor allem mit Präfixen und Suffixen (z.B. Schönheit), seltener auch mit Zirkumfixen gebildet“. «В немецком словообразовании эксплицитные дериваты образуются, прежде всего, при помощи префиксов (vergolden) и суффиксов (Schönheit), peже также при помощи циркумфиксов. Гипотезе о трех видах деривационных морфем следует отдавать предпочтение, поскольку она не нарушает элементарное основное правило о бинарности эксплицитных дериватов. Кроме того, она содействует различению словообразовательных продуктов, при которых префикс и суффикс участвуют в аффиксации во временной последовательности (Präfix und Suffix zeitlich versetzt aufeinanderfolgend ableiten) [4]. Так, при помощи префикса be- образуется на базе суффигированного глагола festigen дериват befestigen. Аффиксация происходит последователь- 
но; в качестве производящей основы можно определить как festigen так и fest: первый шаг fest + -ig = festigen, а второй шаг festigen + be- = befestigen. Деривация при помощи циркумфиксов предполагает одновременность действий двух деривационных морфем: дериват beschönigen аффиксация производящей основы schön при помощи циркумфикса be-...-ig(en): schön + be-...-ig = beschönigen [5]

Циркумфикс (нем. Zirkumfix) (лат. circumfigere перематывать, обернуть'; circum „вокруг“ + fixus „крепко“) circumfix (eng), circonfixe (franz), circonfisso (ital.), cirkumfix (schwed.). «Циркумфиксы - это прерывистые (дискретные) аффиксы, состоящие из двух грамматических морфов и окружающие производящую основу с двух сторон. Поэтому их часто рассматривают представителями одной морфемы, поскольку они только совместно обладают грамматическим значением или выполняют грамматическую функцию». „Zirkumfixe sind diskontinuierliche Affixe, die aus zwei grammatikalischen Morphen bestehen und das Basismorphem auf beiden Seiten umgeben. Man muss sie deshalb zusammen als Repräsentanten nur eines Morphems verstehen, da sie nur gemeinsam eine grammatische Bedeutung oder Funktion erfüllen“ und damit für ein Morphem stehen; dieses komplexe Affix wird für Flexion oder Wortbildung verwendet“; в дериватах "Gerenne", "Gehetze" прерывистая морфема Ge-...-е выполняют функцию субстантивации глагольной основы. Сравни также, например, причастие II: ge-fund-en, ge-mach-t; существительные: Ge-birg-e, Ge-lauf-e; прилагательные: be-brill-t, ent-mensch-t; глаголы: be-erd-ig(en), be-grad-ig(en). Циркумфикс состоит из префигирующей (präfigierend) и суффигирующей (suffigierend) частей или из двух половин циркумфикса (die erste Zirkumfixhälfte und die zweite Zirkumfixhälfte) (циркумфикса). Циркумфиксами являются также „be...ig(en)“ ge-...-ig, в дериватах "beschönig(en)” „gefügig“, поскольку отсутствуют предполагаемые промежуточные этапы деривации как *"beschön(en)" или *"schönig", ““fügig“ или * „gefüg“. Как правило, в теории словообразования циркумфиксы рассматриваются в качестве (свободной) комбинации префикса и суффикса [6, с. 170]. Косвенно такой подход к данному словообразовательному процессу подтверждается понятием «префиксально-суффиксальное словообразование („präfixal-saffixale Wortbildung“). Циркумфикс относится к группе так называемых составных аффиксов, состоящих из двух морфем, которые присоединяются к словам с двух сторон, а составляющие морфемы отдельно обладают другими словообразовательными категориями.

Циркумфиксация (также комбинационная деривация - kombinatorische Derivation) это производство нового слова путем одновременного прибавления к производящей основе и приставки, и суффикса. При циркумфикации основная морфема «расширяется аффиксом как в начале, так и в конце одновременно», при этом оба аффикса выступают всегда совместно. При этом словообразовательную конструкцию нельзя анализировать ступенчато как собственную префиксацию или суффиксацию[7, с. 18]. Циркумфиксация типичный для немецкого языка феномен. Продукт данного процесса называют циркумфиксами, прерывистыми дериватами, парасинтетиками (Parasynthe- 
tika) и т.д.: Ge-hup-e, Ge-zerr-e; be-brill-t, be-reif-t (Pseudopartizipien- псевдопричастия).

Исследователи рассматривают циркумфиксацию одним из основных видов деривации наряду с суффиксацией и префиксацией. Так, Сжигети Имре (Szigeti, Imre) утверждает, что «деривация происходит путем соединения самостоятельных элементов (основ) с такими элементами, которые сами по себе не обладают признаками слова» (Derivation geschieht durch die Verbindung (zumeist) selbstständiger Elemente (Stämme) mit solchen Elementen, die selbst nicht wortfähig sind). В своей работе «Kurze Einführung in die germanistische Linguistik» Сжигети Имре подробно освещает эти три основных вида деривации, а именно суффиксацию, префиксацию и циркумфиксацию [8]. Иногда понятия «циркумфиксы» и «прерывистые морфемы» [9, с. 71], «Zirkumfigierung» и «kombinatorische Derivation» употребляются как полные синонимы [7]. Циркумфиксы, по мнению Кюршнера, - это, прежде всего, комбинация префикса и суффикса, которые могут употребляться самостоятельно независимо друг от друга, например, сочетания ge-...en и ge-...-(e)t (в качестве флексионной морфемы) для образования форм причастия II gesucht, gemacht, gelesen, gefahren; ge-lach-t; Ge-birg-e (ge-...-е в качестве деривационной морфемы) [2, с. 67].

К частотным языковым единицам, связанным с понятием циркумфикс (Zirkumfix) относятся: Zirkumfigierung, Zirkumfixderivation, Zirkumfixderivate, diskontinuierliche Zirkumfixe, diskontinuierliche Morpheme, diskontinuierliche Konstituente, diskontinuierliches Element, kombinatorische Derivation, kombinatorische Ableitung, Parasynthese, parasynthetische Strukturen, präfixal-suffixale Struturen и т.д.

Кроме того, некоторые термины, относящиеся к циркумфиксам, имеют очень широкое, иногда расплывчатое толкование. Так, например, синонимичные понятия „diskontinuierliche Elemente“, „diskontinuierliche Konstituenten“ в лингвистических словарях определяются следующим образом: „прерывистые элементы - это взаимосвязанные языковые элементы, линейная последовательность которых прерывается стоящими между ними другими элементами» „Diskontinuierliche Elemente - zusammengehörige sprachliche Elemente, deren lineare Aufeinanderfolge durch dazwischen stehende andere Elemente unterbrochen ist: ge-reis-t; er ist schnell gelaufen, wo Verbalkomplex ist gelaufen durch das Adverb schnell unterbrochen wird“"10, с. 188]. К прерывистым конституентам Левандовски Т. относит, прежде всего, аналитические формы, напр. сказуемое „ist gekommen“ в предложении «Er ist heute zu spät nach Hause gekommen“ [11, с. 229-230]. Прерывистую морфему В. Кюршнер определяет следующим образом: „Diskontinuierliches Morphem ist Morphem mit einem Allomorph, das aus mehreren Teilen besteht, die nicht unmittelbar aufeinander folgen, sondern durch andere Elemente getrennt sind“ Прерывистая морфема - это морфема с алломорфом, состоящая из нескольких частей, которые не непосредственно следуют друг за другом; между морфема нахо- 
дятся другие элементы: так, в глагольной форме ge-sung-en присутствует прерывистый алломорф /ge-...-en/ морфемы причастия перфекта; соответственно /ge-...-e/ Gebirg-e, Ge-jammer-е и т.д. [2, с. 65]. Глагол zirkumfigieren означает «образовать новое слово при помощи циркумфикса», ср.: Zirkumfigiert ist das Partizip Perfekt (при помощи циркумфикса образовано причастие перфектное), z. B. ge-mach-t, ge-leb-t, ge-waschen, ge-lauf-en. В этом процессе компоненты циркумфикса окружают основу слова. Gemeinsam rahmen die Zirkumfixbestandteile den Wortstamm ein [12].

\section{Литература}

1. Syntax und Morphologie. // www.coli.uni-saarland.de/ tania/ws2010/Folien/VL_05.pdf . Дата обращения: 23.12.2017

2. Kürschner, Wilfried: Grammatisches Kompendium. Systematisches Verzeichnis grammatischer Grundbegriffe. 6. aktualisierte Aufl. A. Francke, Tübingen 2015. - 304c.

3. Fleischer,W. / Barz,I. Wortbildung der deutschen Gegenwartssprache. De Gruyter. Berlin, Boston 2012. - 484c.

4. Die Wortbildung und andere Möglichkeiten der Wortschatzerweiterung. // https://is.muni.cz/el /1421/.../Die_Wortbildung. Дата обращения: 12.02.2018

5. Die Wortbildung - Materialien auf grammis - ids-mannheim.de. // https://www.phil.muni.cz/ge rman/.../wb-grammis-toc.htm. - Дата обращения 26.02.2018г.

6. Polenz, P.v. Wortbildung. In: Althaus, H. P./Henne,H./Wiegand, H. E. (Hg.) Lexikon der germanistischen Linguistik. Tübingen, 1980. - 169-180.

7. Freitag, C. Einführung in die Morphologie " Skript zur Einführungsvorlesung "Uni Konstanz, 2012. - 95 Seiten. // constantinfreitag.de/.

8. Szigeti, Imre: Derivation (Kurze Einführung in die germanistische Linguistik -KEGLI, Band 20) Winter Verlag 2017. - 100c.

9. Simmler, Franz: Morphologie des Deutschen. Flexions- und Wortbildungsmorphologie. Weidler, Berlin 1998. - 346c.

10. Bußmann, Hadumod: Lexikon der Sprachwissenschaft. (3., aktualisierte und erweiterte Auflage) Kröner, Stuttgart 1990. - 904c.

11. Lewandowski, Th. Linguistisches Wörterbuch 1. Quelle \& Meyer 1994. - 415c.

12. Wortbildung durch Derivation bei Verben und Substantiven. // thumulla.com/.../wortbildung_d urch_derivation. Дата обращения 21.12.2017г. 


\title{
Problems of circumfixation
}

\author{
R. G. Gataullin
}

\section{Bashkir State University}

32 Zaki Validi Street, 450074 Ufa, Republic of Bashkortostan, Russia.

Email: gataullinrg@lisr.ru

Circumfixation (also combination (kombinatorische) derivation) is analyzed as the form of creating words by adding both prefix and suffix to the initial morpheme. In the process of circumfixation the basic morpheme "expands with an affix at the beginning and at the end simultaneously", with this both affixes always appear together. Circumfixation is considered to be one of the most basic types of derivation as well as suffixation and prefixation.

Keywords: derivation, circumfix, circumfixation, discrete affix, suffix. 